\section{Função apoio: \\ da mudança institucional à institucionalização da mudança*}

Simone Mainieri Paulon ${ }^{(\mathrm{a})}$ Dário Frederico Pasche ${ }^{(b)}$ Liane Beatriz Righi(c)

Paulon SM, Pasche DF, Righi LB. Support function: from the institutional change to the institutionalization of change. Interface (Botucatu). 2014; 18 Supl 1:809-20.
This paper discusses the constitutive tension of the support function in its institutive task of proposing actions for health work groups that have been limited in their inventive capacity and in their possibilities of producing health for themselves and for others. The initial development of the concept and some dilemmas found in the path of support experimentations are discussed in order to elucidate questions such as: What can be announced as support since its inscription in Brazilian Health System as technology of change sustained by the enhancement of institutional democracy? What are the limits in the exercise of this support function? The reflections propose the problematization of what the (mis)leadings of the experimentations claim concerning what support was, has been and will be.

Keywords: Health public policies. Public Health. Brazilian Health System. support. Institutional analysis. Institutional
O artigo discute a tensão constitutiva da função apoio em sua tarefa instituinte de propor ações junto a coletivos de trabalho em saúde que se encontram limitados em suas possibilidades de produzir saúde para si e para os demais. As elaborações iniciais do conceito e alguns dilemas encontrados no percurso de experimentações do apoio são trazidos ao debate de forma a elucidar questões suscitadas em seu exercício atual, que podem ser assim sintetizadas: O que pode ser anunciado como apoio desde sua inscrição no Sistema Único de Saúde (SUS) como tecnologia de mudança sustentada na ampliação da democracia institucional? Quais os limites a que o exercício do apoio tem nos levado na realização desta função? As reflexões propõem a problematização do que os (des)caminhos percorridos nesta década de experimentações afirmam do que foi, vem sendo e do vir a ser do apoio.

Palavras-chave: Políticas públicas de saúde. Saúde Pública. Sistema Único de Saúde. Análise institucional. Apoio institucional.

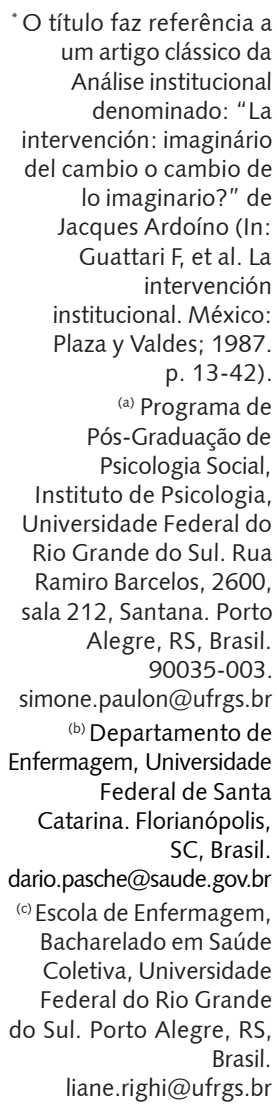


O tema da função apoio - suas finalidades, atributos, possibilidades e as fragilidades que apoiadores vêm encontrando em seus percursos de intervenção - tem sido alvo de inúmeros debates e escritos no campo da saúde coletiva. Não por acaso, recentes publicações e eventos têm-se ocupado de pôr em análise experiências acerca desse modo de trabalhar na saúde e avaliado os efeitos que podem ser percebidos nas redes de saúde a partir das intervenções desencadeadas por um, já significativo, contingente de apoiadores institucionais.

Mas o que da função apoio provocaria tanta polêmica ou teria de tão instigante a ponto de suscitar, em pouco tempo de experimentação, tamanha discussão? Invenção da primeira década do século, o apoiador institucional surge em diferenciação à figura clássica de um supervisor do trabalho (de inspiração da gestão do trabalho na área industrial) e, também, ao analista institucional.

Com a finalidade precípua de contribuir para que coletivos organizados para a produção de saúde possam colocar em análise seus modos de trabalhar, e revisando-os produzirem mais e melhor saúde, os apoiadores institucionais passaram a ser demandados por diversas organizações de saúde ${ }^{1}$. Desde o ano 2000, quando Campos ${ }^{1}$ assim denomina a função desses agentes articuladores de redes (de conversação, de produção de saúde), e passa a trabalhar na perspectiva de formá-los, a demanda de vários segmentos e organizações da saúde para compor equipes com apoiadores institucionais tem sido crescente.

Nesse cenário, algumas secretarias estaduais e municipais, bem como instituições privadas que têm feito gestão de serviços de saúde (fundações, organizações sociais etc), optaram por disparar cursos, formar apoiadores e, inclusive, realizar concursos públicos para contar, em seus quadros, com apoiadores institucionais. Em nível federal, o próprio Ministério da Saúde desencadeia uma série de processos de formação de apoiadores a partir de 2006, e, no ano de 2012, reorganiza a gestão do apoio integrado, contratando e formando mais de duas centenas de apoiadores para o Programa de Apoio Integrado².

Temos ocupado a posição de formadores desde diferentes lugares institucionais (universidades, gestão, atenção), eventualmente na condição de gestores (de projetos ou junto a segmentos do Estado), tanto quanto de apoiadores institucionais - função que também exercemos em diferentes territórios - algumas vezes, nos mesmos em que somos formadores e/ou gestores. Isto permite-nos compartilhar algumas questões que, constantemente, nos fazemos e que têm sido recorrentes entre os mais diversos apoiadores com quem temos trabalhado: que poder instituído tem/deve ter o apoiador para implementar mudanças na organização do trabalho? Desta singela pergunta, decorrem outras tantas. É possível propor mudanças que também desejamos e as quais nos afetam diretamente enquanto trabalhadores? É possível apoiar coletivos dos quais fazemos parte (questão que sempre acompanhou e dividiu os analistas institucionais)? A função apoio é compatível com funções de gestão? E é possível exercê-la plenamente desde um lugar instituído (cargo) de apoiador?

No momento em que o tema do apoio deixa de ser preocupação restrita a eventuais gestores em territórios bem demarcados, ou pesquisadores com referências teóricas bem delimitadas, para figurar como uma discussão circulante entre trabalhadores e setores dos mais diversos territórios e formações, entendemos ser uma boa hora para uma reflexão acerca de seus efeitos.

Para tanto, partiremos de um breve percorrido acerca de como se constituiu a função apoio até algumas das definições que lhe são atribuídas; passaremos por um debate sobre possíveis relações entre aquilo que vimos experimentando no exercício do apoio e o que vimos aprendendo na análise das experiências produtoras e produzidas pelo conceito. Neste ponto, tomaremos a recente proposição (acompanhada de processo de formação) do Ministério da Saúde de um "apoio integrado" como foco de observações, já que a estamos compreendendo, nos termos institucionalistas adotados no âmbito deste estudo, como experiência analisadora da função apoio em nossa realidade. Finalizaremos a discussão enfocando, mais especificamente, o tema anunciado pelo título do artigo acerca de um possível processo de institucionalização que a função apoio possa estar sofrendo para provocar alguns questionamentos e apresentar posicionamentos sobre os usos e utilidades do apoio no cenário atual da saúde coletiva em nosso país.

Ao levantar aspectos crítico-analíticos da função apoio desde experimentações em campo desenvolvidas em mais de uma década, que têm permitido a atualização de concepções e modos de fazer o apoio, este artigo pretende contribuir com as avaliações acerca de como o exercício dessa nova modalidade de trabalho em saúde tem interferido nos modos instituídos de se trabalhar neste campo. 


\section{Da formulação de uma função: experimentações em curso}

Interessa-nos, especialmente neste momento, refletir acerca de como o exercício do apoio se relaciona, no campo da saúde, com o marco conceitual em que foi originalmente formulado. Quais elementos conceituais fundantes da função apoio, que permitem defini-la como inovação tecnológica na gestão do trabalho, têm comparecido, ou sido rejeitados ou, mesmo, negligenciados nas experiências de apoio em curso?

A situação que se quer superar e a transformação que se quer viabilizar, inclusive como efeito da atuação do apoiador institucional, é apresentada de forma clara por Gastão Campos, que diz: "preocupados com a tendência do SUS, de reproduzir o que pretendíamos superar, sugeri instituírem-se processos da reforma da reforma. Isso é, cuidar de reformar o modelo tradicional de gestão e, ao mesmo tempo, instituir mudanças no modelo de atenção" 3 (p. 113).

Como todo o processo de instituir mudanças, a proposição de se alterar modelos de gestão há muito instituídos nas organizações de saúde não é isenta de conflitos. Os contratos institucionais, ao promoverem inscrições e pertenças nas organizações, definem lugares, tarefas e responsabilidades, não sendo raro marcações bastante rígidas que permitem, por mais desconforto e desigualdade que isso gere, que cada um saiba, a menos, "qual o seu quadrado". A proposta do apoio mexe com estas "zonas de conforto", muitas vezes acomodadas como ganho secundário e, por isso, há certo grau de tensão que sempre acompanha a tarefa do apoiador, pois ela sempre vai mobilizar diferentes forças: as conservadoras, para manter posições garantidas; e as forças disruptoras, mais dispostas a enfrentar os riscos e ansiedades geradas pelo que o novo possa desterritorializar ou vir a exigir.

Neste sentido, vale a análise feita por Sônia Fleury ao retomar a discussão sobre os princípios éticopolíticos, normativos e operativos que têm sustentado o movimento da reforma sanitária brasileira ${ }^{4}$. Entende a autora que as profundas mudanças cultural, política e institucional, mobilizadas para viabilizar o projeto contra-hegemônico que levou a saúde ao reconhecimento como relevância pública, que representou um novo patamar civilizatório da política pública de saúde no Brasil, encontra algum esgotamento. Fleury ressalta, nessa direção, que, como todo processo instituinte, o caráter de movimento que desencadeou, e, em grande parte, garantiu muitas das conquistas da Reforma Sanitária Brasileira, não pode ser mantido ad eternum, e isto vai implicar a inclusão de novos atores e novas correlações de forças no jogo político. Como explica a autora:

O paradoxo da reforma sanitária brasileira é que seu êxito, ainda que em condições adversas e parciais, terminou por, ao transformá-la em política pública, reduzir a capacidade de ruptura, inovação e construção de uma nova correlação de forças desde a sociedade civil organizada. Em outras palavras, o instituído se impôs ao instituinte, reduzindo o caráter libertário e transformador da reforma. A constatação de que a iniquidade estrutural da sociedade brasileira atravessa hoje o sistema único de saúde é a possibilidade de retomar o combate pelas idéias igualitárias que orientaram a construção deste projeto. Para tanto, resta a questão da construção permanente do sujeito, aquele que poderá transformar novamente o instituído em instituinte, para de novo institucionalizar-se. ${ }^{4}$ (p. 751)

Ressalte-se, aqui, que, ao finalizar com este trecho seu argumento - e, com ele, o próprio artigo que analisa os "dilemas entre o instituinte e o instituído" da reforma sanitária brasileira -, a autora afirma o caráter processual e inevitável de cristalização dos processos institucionais inscritos em movimentos de democratização. Com esse alerta ela não está, evidentemente, desvalorizando a potência instituinte que os novos valores ético-políticos e práticas sociais incluídos e produzidos no SUS tiveram e ainda têm. Ao se institucionalizarem, ao conquistarem a estabilidade das estruturas sociais, políticas e institucionais, os novos valores e práticas (inclusive de cuidado e de gestão) não perdem seu sentido de inscrição e de construção histórica da mudança e transformação social. Ao contrário: o caráter instituinte de todo processo crítico-propositor de novos modos de vida e trabalho só pode ser dito como parte de um movimento criativo - no caso da reforma sanitária - porque tende à institucionalização. Ou seja, se as forças instituintes se fizeram presentes e passaram a constituir a 
realidade social, ocupando espaço institucional até então marcado por movimentos estabilizadores, de conservação da realidade constituída e dos processos de subjetivação dela derivados, é sinal de que lograram êxito enquanto movimento crítico. Processos instituintes que encontram a estabilidade social, política e institucional, inefavelmente, se depararão, em algum momento da história, com movimentos críticos, os quais, no jogo político, podem ganhar espaço e fazer avançar novos processos instituintes cuja potência pode fazê-los assumir sua vocação de subverter o que está posto. Como dizia Marx, tudo está em movimento, exceto o próprio movimento da história que é constante, imutável.

Tal discussão, neste sentido, oferece um bom suporte para pensarmos a atualidade da função apoio e, no rastro da reflexão proposta por Fleury, analisarmos outros dos "dilemas entre o instituinte e o instituído" deste delicado e contra-hegemônico processo que continua sendo a construção do SUS.

Ao propor a função apoio como tecnologia que assume a crítica à racionalidade gerencial hegemônica e que se insere nos processos de produção de saúde para construir outras racionalidades e novas formas de gestão, Campos ${ }^{5}$, em seu conhecido artigo denominado "O anti-Taylor", já propunha um novo arranjo para as instituições de saúde. Ele sugere alterações significativas nos organogramas tradicionais, com alteração no desenho dos departamentos, supressão dos tradicionais cargos de chefia e estímulo à atuação matricial e ao trabalho de equipes, denominadas, pelo autor, de Coletivos Organizados para a Produção. O conceito de Unidades de Produção utiliza a referência da interdisciplinaridade, aproxima e aglutina trabalhadores que atuam em um mesmo território, com um mesmo objeto ou com os mesmos usuários ou serviço de saúde ${ }^{3}$.

Essa elaboração articula e combina mudanças em dois elementos institucionais que, em geral, têm sido vistos de forma isolada nas formulações de mudança. De um lado, propõe alterações na estrutura de funcionamento das organizações a partir de um processo de achatamento da arquitetura organizacional, aproximando trabalhadores e gestores, e estes com os usuários, conectando processos de trabalho antes dispersos. De outro lado, apresenta uma nova dinâmica para as relações de poder nas organizações, sustentada na criação de dispositivos de gestão do trabalho que coloca os diferentes sujeitos que comungam situação de trabalho em processos mais colaterais de comunicação, aproximando-os e, de certa forma, forçando o encontro e o contato com a diferença. Neste ponto, o apoio desponta como um recurso para a problematização dos modos de gerir e de cuidar e para a produção de mudanças, então originárias de processos de coletivização, que expressam um plano comum. Atualizada na dinâmica das rodas, podemos pensar que esta construção de um plano comum tende a não se cristalizar, porque sujeita à avaliação constante do coletivo que a compôs.

O processo de produção de um projeto comum por equipes de saúde, a pactuação de processos de trabalho, se dá junto com um processo de diferenciação, de singularização dos sujeitos. Todavia, não é propósito desse contato entre alteridades homogeneizar os sujeitos que compõem coletivos organizados para a produção, exatamente pela importância de se distinguirem, por se enriquecerem nesta pluralidade. Além disso, se entendemos a rede de saúde e a própria organização do trabalho em equipe como um conjunto de nós interconectados, a identificação das Unidades de Produção, dos coletivos e de seus processos de trabalho já é efeito de uma proposta de gestão e de nossa intervenção na condição de apoiadores.

Neste sentido, a contração de responsabilidades que se estabelece entre apoiador e coletivo apoiado, se reveste de especial significado e dá o tom, como em toda relação de confiança que se inaugura, do tipo de vínculo que, a partir dali, será estabelecido.

É constante, na obra de Gastão Campos, a ideia do apoiador vinculado a coletivos de saúde em uma relação de compartilhamento de compromissos em que se estabelecem os parâmetros e a dinâmica do trabalho do apoio. Dito de outra forma, o apoio depende de certa estabilidade, que se verifica na contratação de certo número de encontros, dos temas a serem analisados e dos modos de construção das alternativas para lidar com os problemas e inventar soluções para enfrentá-los. Entram, também, neste acordo as possibilidades de o grupo colocar em discussão a própria experiência de grupalização, nesse movimento de roda de análise e de coletização, no qual o apoiador se insere como um terceiro.

Essa estabilidade construída pelo contrato entre equipe de saúde e apoiador estabelece os requisitos ético-políticos para o apoiador se constituir como uma referência importante para o grupo. Em que pese o fato de contratos estabelecerem os parâmetros para o exercício do apoio, recontratar é parte do 
movimento da construção da grupalização. Todavia, equipes que atuam em saúde e que lidam com situações muitas vezes extremas, com alto grau de responsabilização e condições nem sempre adequadas, não deveriam ser submetidas a sucessivos novos contratos que implicam exposição a novos apoiadores, novas pactuações exigidas por negociações de expectativas diversas a cada encontro. São situações que implicam, sempre, alguma medida, desgastes na relação com as equipes. Assim, o apoio se diferencia de uma visita, de um contato, ou, mesmo, de ação que é típica de assessorias e consultorias: entrar em contato com coletivos para anunciar a eles, desde um suposto saber, o que o grupo deve fazer. $\mathrm{O}$ apoio se estabelece como referência de confiança e só pode existir em um contrato que lhe dá possibilidades de permanência, cuja inscrição o insira em um processo de grupalização, sem o qual a construção coletiva não se realiza.

Voltar ao mesmo coletivo, suportar a crítica ou a explicitação de situação que inviabilizou a realização do que foi acordado, reposicionar-se, insistir, mudar a velocidade ou abandonar caminhos (mesmo aqueles que nos custa tanto abandonar, que pareciam tão promissores...), recontratar, avaliar junto ao coletivo, comemorar avanços, compreender e superar as derrotas, buscar mais e novos suportes conceituais, dialogar com eles, jogar alguns fora, procurar novas explicações (porque as que tínhamos já não dão conta do que a vida foi demandando)... tudo isto faz parte do cotidiano do apoio e compõe a dinâmica de trabalho do apoiador.

Daí dizermos, também, que a formação do apoiador está relacionada às experimentações do apoio. É necessária certa permanência no apoio e num coletivo para se constituírem as condições de possibilidade do trabalho de apoio. É necessário um tempo para que o mesmo coletivo compartilhe projetos e expectativas e para que a função apoio se realize como tal. É neste aspecto que o apoio se diferencia de outras possibilidades de encontro, como visitas, participação em capacitações ou atualizações. Isso tudo pode ser muito importante, mas não há, necessariamente, o estabelecimento de confiança e de vínculo se não há continuidade, pois, nessa exposição esporádica, o apoiador não terá condições de se constituir como referência ao grupo, cuja construção permitirá, ao grupo, frequentar dispositivos e settings construídos como verdadeiros espaços para se analisar, se reposicionar e contratar tarefas. A esse respeito, a afirmativa de Campos é pontual e singela: "A relação entre o Apoiador e a Equipe é mediada por contratos [...] recomenda-se que o trabalho de co-gestão comece com a construção do contrato estabelecendo expectativas, objetivos, regras, método de trabalho e o que mais for necessário"6 (p. 187).

Assim, o cuidadoso estabelecimento de contratos e constantes revisitas a eles é condição para atualização da função apoio e consequente legitimação do apoiador. Outra questão que diz respeito às exigências conceptuais que o exercício do apoio tem exigido, e que, em nossa avaliação, ainda não está resolvida, é a de quem são os apoiadores e quais os coletivos apoiados. Ou seja, com qual Coletivo Organizado para a Produção ou com qual Unidade de Produção estamos contratando apoio? Respostas para esta pergunta podem nos ajudar a não reduzir o apoio à realização de oficinas, cursos ou encontros esporádicos cuja periodicidade e relação de referência não se consegue sustentar. Provavelmente, muitos apoiadores responderiam hoje que apoiam territórios tão grandes (municípios inteiros ou departamentos de grandes organizações, quando, em outros tempos, foram equipes ou pequenos setores de um hospital, por exemplo) ou um conjunto tão diverso de grupos que a sua prática não tem conseguido mobilizar a coprodução de análise de temas, de avaliação solidária (e crítica generosa, seguindo conselho de Gastão Campos).

Trazendo o exemplo para um campo que nos é conhecido e caro, falar sobre ampliação da clínica para trabalhadores e gestores de uma secretaria municipal de saúde não é o mesmo que apoiar uma equipe no desenvolvimento de um Projeto Terapêutico Singular (PTS). A primeira situação é importante e necessária para disseminar a ideia, ganhar aliados, espraiar uma teoria nova. Tudo isso é importante, mas é no cotidiano do trabalho das equipes que vão aparecer as dificuldades, que vão ser reveladas complexas tramas entre aquilo que passa a ser reconhecido como responsabilidade do grupo e o que cada um reconhece como sua responsabilidade ou está disposto a contratar com o coletivo. Assim, o PTS mobiliza conteúdos novos nas reuniões da equipe, exige novas competências e características dos coordenadores, convoca novas capacidades para compor com os interesses dos trabalhadores e dos usuários. 
Para melhor exemplificar essa posição, tomaremos uma proposta recente de exercício do apoio e em curso no território nacional a partir de um projeto do gestor federal. A experimentação do apoio no Ministério da Saúde tem trazido, ao exercício do apoio, novos desafios. Trata-se de um apoio que, no Ministério da Saúde, tem sido denominado de "apoio integrado" na medida em que busca integrar várias áreas que, tradicionalmente, desenvolveram ações de forma isolada, fragmentária, marcadas pelo isolamento e a lógica prescritivo-normativa, típica da racionalidade programática. A ênfase do apoio integrado passa a ser o desenvolvimento de projetos de intervenção mais articulados, com agendas mais integradas e um regime de cooperação no desenvolvimento e gestão nas regiões de saúde: um apoio para regiões de saúde. Sem dúvida, um avanço. Mas quem, nas regiões? Quais seriam as Unidades de Produção a que estes apoiadores estariam se vinculando?

O documento do Ministério da Saúde "Caderno de Referência para a Formação de Apoiadores" reconhece o ano de 1998 como data em que a expressão 'Apoiador Institucional' começa a ser utilizada, e o ano de 2003 como o ano das primeiras experiências de apoio (o apoio integrado) no Ministério da Saúde?.

Há, neste documento de formação, ênfase na relação interfederativa sustentada na cooperação:

As ações de apoio institucional integrado do Ministério da Saúde deverão priorizar os projetos de cooperação nas regiões de saúde, de modo a promover a ação solidária e cooperativa entre os gestores, objetivando garantir acesso resolutivo e com qualidade de acordo com o Decreto $n^{\circ}$ 7.508. O apoio institucional proposto pelo Ministério da Saúde implica um modo de relacionar com outros entes (municípios, estados, regiões), para além das normas, além da indução financeira, aprendendo com os efeitos, aprimorando a prática gestora a partir da análise de resultados em grupos plurais e implicados positivamente com mudanças para melhoria do SUS.? (p. 17)

O documento também revela um esforço para apresentar (e diferenciar) o apoio institucional do apoio matricial. É desta diferenciação que emerge a proposta de uma 'Equipe de apoiadores temáticos' que desenvolve apoio matricial no Ministério da Saúde, proposta que inclui apoiadores institucionais de um dado território.

No MS, o apoio matricial pode ser desenvolvido por uma equipe de apoiadores temáticos (rede cegonha, saúde mental etc.) ou de uma área/política específica (vigilância em saúde, saúde do homem, coordenação geral de hospitais etc.) com os apoiadores institucionais de um dado território. A relação entre apoiadores institucionais não é de mão única: pode ser demandada pelos apoiadores estaduais/regionais ou locais ou ser ofertada, quando considerado estratégico num dado território.? (p. 17)

Seria, então, o apoiador de rede temática um apoiador do Ministério da Saúde? Neste caso, qual seria o foco do apoio? E quem seria o "cliente da intervenção"? É o próprio Ministério o Coletivo Organizado para a Produção a ser apoiado? Ou se trata de um apoio matricial que se faria a uma Unidade de Produção formada por apoiadores institucionais vinculados aos territórios?

Neste mapa teórico-metodológico, cabe reforçar a distinção entre o apoio matricial - que trata de conhecimentos ou tecnologias específicas -, e o apoio institucional, relacionado à inovação e suporte aos coletivos. No mesmo documento oficial supracitado, do gestor federal, a diferenciação entre as duas formas de apoio está colocada nestes termos:

O apoio institucional implica criar espaços de conversação, de explicitação das diferenças, de pactuação do que fazer, do como fazer. Portanto, é necessário algum grau de cogestão para que trabalhadores possam olhar o próprio trabalho, suas relações dentro do serviço e as relações das equipes com os usuários, a fim de que mudanças possam ocorrer. Nesse mesmo sentido, entende-se por apoio matricial o aporte de conhecimentos/tecnologias específicas 
de uma equipe de trabalho a outra, proporcionando troca de saberes entre todos os participantes das equipes matriciadora e matriciada? (p. 17)

O texto parece, portanto, indicar que, entre estas duas vias de institucionalidade para o apoio, a 'necessidade de algum grau de cogestão' é o que mais claramente delimita a definição do apoio institucional. Mas como tem comparecido este aspecto definidor do apoio institucional nas práticas concretas em que ele se efetiva?

\section{Dos limites e potências do apoio para interferir na capacidade de se produzir saúde}

Todo este percurso que viemos percorrendo sobre a função apoio, que começou a ser enunciada no fim da década de 1990, para, no início dos anos 2000, se constituir como um método, buscou demonstrar que sua experimentação junto a equipes de saúde chega ao final da primeira década do $3^{\circ}$ milênio desgastada, quase que perdendo sua especificidade e capacidade de designar ações minimamente demarcáveis no campo empírico. Isto nos força a constatação de que nem tudo que se diz fazer e se tem feito em nome do apoio pode ser credenciado à ideia original de apoio e da função apoio, cuja ética - a atitude apoio - se vincula às estratégias de produção da autonomia e a ampliação da democracia institucional, ampliando o valor de uso das organizações de práticas de saúde e transformando o trabalho em campo de criação.

Nessa direção, duas questões tornam-se relevantes, e seria preciso discriminálas a fim de resguardar aquilo em que vale a pena insistir e, talvez, aquilo do que tenhamos que nos desapegar, de nossos conceitos-ferramentas, para fazê-los atuar na recriação de nossos modos de gerir e de cuidar. Trata-se, aqui, tentando ser mais exatos, de distinguirmos o apoio como método e como função.

O apoio, como temos visto nas produções derivadas 'do' e 'no' SUS, se reveste de rigor, de um lado, metodológico, e, de outro, conceitual. Apesar de uma louvável ampliação na utilização da função apoio nas mais diversas organizações de saúde, citado em discursos plurais e demandado em projetos políticos não menos variados, há que se demarcar, também, certa banalização do termo. Parece que esse conceito-ferramenta que nos é tão caro tem virado uma palavra jogada ao vento. Isso porque sua inscrição como prática nas organizações de saúde parece nem sempre coerente com a discursividade ética que justificou sua criação. Em pouco mais de uma década, chegamos a um lugar comum, parecendo que todos, em quase todas as organizações de saúde, usam o recurso do apoio para ampliar sua capacidade de realização de resultados e metas, para dar conta de sua missão.

Não que a rápida apropriação do apoio seja em si um problema, pois isso anuncia um primeiro efeito desejável; dizer que se usa esse recurso em boa parte das organizações do SUS é já um efeito positivo, pois aponta a existência de espaços coletivos nas organizações de saúde que, de alguma forma, colocam em questão sua capacidade de produzir saúde. Se uma demanda de apoio

(d) Expressão-título do livro de Christopher Lasch "O mínimo eu: sobrevivência psíquica em tempos difíceis" (São Paulo: Brasiliense; 1986), que debate a cultura narcisista como característica da era moderna. constituiu-se em algum momento é porque, de algum modo, a utilização de uma tecnologia de interferência na organização do trabalho fez-se necessária para melhor produzir saúde. Mas exatamente aqui, nessa extensividade, nesse plano topográfico, na virtude dos tempos em que vivemos - da hipervelocidade, da superinformação, tempos do "mínimo eu"(d) - é que reside a questão que aqui propomos à reflexão: o que pode ser anunciado como apoio, desde sua inscrição no SUS, como tecnologia de mudança sustentada na ampliação da 
FUNÇÃO APOIO: DA MUDANÇA INSTITUCIONAL ...

democracia institucional? E quais os limites a que o exercício do apoio tem nos levado na realização desta função?

Estamos claramente defendendo que nem tudo pode ser associado à ideia de apoio. E, neste sentido, caberia, ainda, no âmbito deste artigo, apontarmos alguns elementos que permitam ilustrar essa posição.

Primeiro, o apoio guarda um sentido ético-político, expresso em seu método, que pode ser traduzido em uma diretriz muito objetiva: apoio é tecnologia para ampliar a democracia institucional. Nesta perspectiva, não só não pode ser "dito", nomeado junto a qualquer prática institucional, como é incompatível com boa parte do que se instituiu como trabalho em organizações de trabalho hierarquizadas, piramidais, que nos rodeiam.

Neste sentido, defendemos a ideia de que a ampliação da eficácia das práticas ou uma maior eficiência das organizações de saúde deveria resultar como efeito secundário, algo que seria produzido como derivado da mudança nos modos de organizar o trabalho. Em outras palavras: melhor e mais saúde seriam resultado não de uma ação direta derivada de um plano de metas definidas pela organização, para o que, em geral, se mobilizam trabalhadores, mas como derivação, resultado, produto de negociações e pactuações entre trabalhadores e com gestores, que resultariam na alteração de processos de trabalho em saúde, que, então, passariam, como acordo comum que estabelecem corresponsabilidades, a ser organizados de forma mais coletiva e menos fragmentada. Esse sutil deslocamento, que Passos e Benevides ${ }^{8}$ vão denominar de hodos-meta-trocar o primado da meta pelo do próprio caminhar, que traça seu percurso afirmando a força da experiência concreta dos coletivos como guia -, impõe reconhecer que as mudanças na oferta e na qualidade da atenção dependeriam de investimentos desejantes no trabalho, cujo efeito seria a produção de novos sentidos e compromissos para o trabalhador, então em melhor condição de recriar os modos de trabalhar porque ali sua marca distinta de trabalhador comparece como obra ${ }^{1}$.

Dito de outra forma, sem mexer na organização do trabalho, sem reverter as estruturas heterônomas, verticalizadas e alienantes da organização taylorista do trabalho, dificilmente se produzirá mais saúde (pelo menos de forma sustentável). Neste ponto Gastão Campos não faz rodeios:

O que se pretende descrever aqui é um Método de Gestão que, apoiando-se em toda esta tradição, almeje mais do que adaptar e moldar Sujeitos. Na realidade, realizar um duplo trabalho. Por um lado, assegurar o cumprimento do objetivo primário de cada organização produzir saúde, educar, etc -; e por outro, ao mesmo tempo, permitir e estimular os trabalhadores a ampliar sua capacidade de reflexão, de co-gestão e, em decorrência, de realização profissional e pessoal. [...] Criar espaços de democracia ampliada, processos produtores de sujeitos-cidadãos, grupos capazes de impor resistência às determinações adversas do meio. ${ }^{6}$ (p. 865)

Ao acentuar esta dupla missão que as organizações têm, especialmente no caso da saúde - na produção de serviços e de sujeitos ao mesmo tempo - o sanitarista apresentou uma reflexão fundamental que ampliou, em muito, nossa capacidade de compreensão e de ação política. As organizações de saúde visam à produção de saúde, convocatória que deriva de seu "valor de uso". Mas elas também produzem sujeitos, portanto, são máquinas subjetivadoras: produzem subjetividades.

E, em relação aos trabalhadores, arriscamo-nos a dizer que o sentido de estar ali - no trabalho - não é necessariamente nem primeiramente produzir saúde, senão estariam resignados à condição de meros "recursos". Aliás, em geral, é assim que são compreendidos e, na maioria das vezes, denominados: "recursos humanos do SUS", igualando-se a outros, como os materiais, financeiros etc. É precisamente esta concepção que considera as pessoas "insumos na produção de saúde" que deve ser revertida, caso queiramos construir as condições políticas e éticas para revisar os modos de organização dos processos de trabalho que permitam reinventar a saúde.

Como todo "bom problema" - já que parte de uma questão intricada - a solução encontrada é cheia de novos problemas. Se os trabalhadores não são insumos, como, então, produzir outro sentido 
para o trabalho em saúde que não caia em outra polarização, agora localizada no interesse quase absoluto do trabalhador?

Encontramos uma resposta possível no que - não por acaso - constitui-se em diretriz da Política Nacional de Humanização, que nos remete ao sentido para o qual a função apoio foi criada e sobre o qual o método do apoio se assenta. Essa resposta vai em direção à necessidade de se ampliar a democracia institucional e a experiência democrática nas organizações de saúde, entendendo democracia como processo de apropriação mais coletiva. Mas de que apropriação estamos falando para não se afirmar mais uma apropriação privatista? Falamos da apropriação da possibilidade de fazer a gestão do seu próprio trabalho. Portanto, a alternativa é a inclusão de trabalhadores, usuários e gestores na construção da própria instituição, das organizações de saúde. Daí, a afirmação de que uma política que problematize os processos de produção da atenção e da gestão do SUS só pode realizar-se na relação intrínseca com um método que opere a inclusão, acionando processos cogestionários. Como referem Pasche e Passos:

O apoio institucional é um dispositivo com o qual temos apostado; como dispositivo, ele tem uma função de referência, isto é, o apoiador põe a funcionar determinado processo junto ao coletivo, aciona um movimento de mudança das práticas de saúde e acompanha o caminho nesse processo de mudança dos modelos de atenção e gestão na saúde. Sua função de referência garante um mínimo de regularidade em meio ao processo de mudança, sendo um índice dos vínculos que mantém unido certo coletivo. ${ }^{9}$ (p. 432)

A cogestão é, assim, uma forma de produção de democracia, porque possibilita que a maioria dos trabalhadores pense e interfira na organização dos modos de trabalhar. Além disso, a cogestão permite reaproximação do trabalhador com sua própria obra, que é sempre coletiva, derivada de um complexo arranjo de componentes e de organização do trabalho. Pensamos, portanto, o apoio como uma função exercida em coletivos, com equipes que compartilham situações de trabalho não raro muito densas, duras, e que demandam suporte de alguém que ajude a pôr os processos naturalizados em análise.

O apoio assume, assim, a conotação de uma função que se situa na delicadeza do encontro entre esses grupos/equipes e alguém que cumpre esse papel de apoiar. Alguém que, antes de tudo, propõese a lidar com as relações com vistas a

[...] construir múltiplos reposicionamentos, cuja direção deve ser afirmativa de grupalidades mais solidárias e mais capazes de propor e realizar práticas de gestão e de cuidado em consonância com aquilo que do ponto de vista social e político tem sido tomado como justo, ético e tecnicamente adequado. ${ }^{9}$ (p. 433)

Estamos falando de um dispositivo cuja orientação ou princípio não pode estar desprovido desse profundo senso ético e político que é, na dobra eficácia/eficiência, a exigência da realização do valor de uso das organizações, da produção de novos sujeitos capazes de incluir seus interesses e necessidades no jogo da organização do trabalho, sem que sabotem ou capturem o trabalho em saúde desde seus interesses imediatos, sobrepondo aos interesses coletivos.

Estamos, pois, falando dos limites do exercício do apoio institucional, desde lugares instituídos, sem que ele se descaracterize em seu compromisso original - justificativa para criação de uma tecnologia de interferência no enrijecimento das organizações - com os processos de análise crítica junto aos coletivos demandantes de maior participação nos processos de gestão e produção de saúde.

\section{Considerações finais}

O apoio institucional se inscreve no SUS como alternativa para se produzirem mudanças nos modos de gerir e de cuidar, considerando, de um lado, os interesses institucionais, que devem ser afirmativos 
dos direitos dos cidadãos e, de outro lado, os interesses e necessidades dos trabalhadores de saúde. A tradição nos processos de mudanças em geral pouco altera a racionalidade gerencial hegemônica, reafirmando, na maioria das vezes, o papel heterônomo que a gestão do trabalho exerce sobre o trabalhador.

Apoio, nesse sentido, se assenta em um compromisso ético de produzir mudanças das organizações de saúde que promovam uma nova inscrição do trabalho que nelas se realiza, que não pode, sob o risco de perda de eficácia, ser completamente regulado. Logo, impõe a construção de espaços (coletivos) para a análise do trabalho (modos de gestão) e contratação de tarefas, as quais devem garantir melhor eficácia e efetividades das práticas, como dobra de uma melhor realização e satisfação do trabalhador.

A produção coletiva de novos arranjos nos processos de trabalho, afirmativa da democracia nas relações, não se faz (nem tem sido feita) sem a emergência de processos conflitivos, que, via de regra, geram diferentes graus de sofrimento, pois exigem reposicionamentos subjetivos, mobilizam identidades e corporações inscritas na tradição clássica da divisão social do trabalho em saúde, eivada de relações cristalizadas de poder. São movimentos que exigem capacidade de manejo de conflitos na direção da produção de novas contratualidades, portanto, requerem rearranjos sobre aquilo que foi sendo instituído como responsabilidades e competências numa lógica que demanda superação.

Assim, a função apoio se exerce menos para a obtenção dos fins da organização (metas e resultados) e mais para a produção de reposicionamentos no trabalho, os quais resultariam, então, em novas contratualidades capazes de ampliar a capacidade de as equipes e organizações de saúde produzirem mais e melhor saúde.

É nesse ponto que insistimos que o apoio tem um compromisso ético-político que o reveste de uma função que é de ativação e fomento de grupalidades, mais solidárias e corresponsáveis. Logo, uma ação mais instrumental ou presidida, essencialmente, pela racionalidade instrumental, cujo compromisso é com a realização de metas e resultados estabelecidos alhures, longe dos espaços concretos onde atuam as equipes de saúde, tende a reduzir, senão a negar, o papel instituinte do apoio.

Não que o apoio não tenha compromissos com metas e resultados. Ao contrário, Gastão Campos, quando nos oferta esse conceito-ferramenta, afirma que o compromisso é com a produção de mudanças nas organizações de saúde. O que ele chama atenção, e o que faz inscrever seu método como inovação gerencial, é que, no jogo institucional, as metas da organização constituem-se como uma das demandas, que, somadas às demandas originárias de interesses de trabalhadores e usuários, devem ser processadas, sob o risco de as planificações virarem tão somente documentos destinados às "gavetas" ou a alguma "nuvem virtual", se quisermos modernizar o ato de escanteá-los.

O apoio, nessa perspectiva, se coloca no estranho e complexo lugar de promover o debate, trazer à tona contradições, produzir analisadores sociais e, no manejo disso tudo no grupo, nas equipes, produzir novos valores no trabalho em saúde, afirmativos de modos de fazer que reconheçam direitos e dignifiquem o trabalho.

A inscrição do apoiador na organização de saúde, sobretudo aqueles demandados pelas gerências (instâncias e atores que concentram poder normativo), deve ser sempre problematizada e inevitavelmente colocada em análise. Independentemente do lugar institucional ocupado pelo apoiador, a ética do apoio coloca, como compromisso, a interrogação incessante sobre seus modos de interagir e de intervir nas equipes e os propósitos de sua ação, que devem ser explicitados e comparecer na análise das implicações nos processos de construção dos contratos (com quem demanda, como e para quem o apoio se apresenta como oferta). Sem isso, o risco de se transformar o apoio em uma intervenção ordinária de inspiração instrumental, que se apresenta mais como um recurso gerencial para que as equipes cumpram melhor o que a direção determinou, é sempre uma ameaça ao cumprimento da função apoio. E isso, afirmamos claramente, deveria ser denominado por outra expressão que não apoio.

Neste sentido, mesmo compreendendo a intenção afirmativa de uma ética fiel aos princípios solidários, coletivos e democratizantes do apoio, contida nas inúmeras referências feitas a seu "nãolugar", a suas práticas operadas no "entre", gostaríamos de distinguir a posição aqui assumida em relação à não-definição a priori de um lugar institucional para o apoio. Tão importante quanto não identificar um lócus no poder instituído, desde o qual um apoiador possa outorgar-se a função de disparador das mudanças, é não jogarmos a ideia do apoio para um extremo oposto, deixando-a envolta 
em um grau tal de abstração e mistérios que ninguém entenda, exatamente, do que se trata ou para que, afinal, pode servir. Preferimos, por este motivo, atribuir um lugar mutante ao apoiador, reforçar a importância de sua não-fixidez a um dado lugar, já que importa mais a qualidade da oferta e clareza do contrato que ele possa fazer junto ao coletivo, apoiado em seu processo de mudança, e menos a posição nas hierarquias e organogramas a partir dos quais ele vai operar tais mudanças. Importa, mesmo, é a possibilidade de manter-se em movimento.

A ênfase aqui é na ideia de que apoio que não oferta, que pouco oferta ou que oferta genericamente - sem deixar claro o compromisso com a análise crítica dos modos cristalizados, com que boa parte das equipes lidam com suas relações de poder - corre o risco de se transformar em tecnologia, tão somente, de fomento à organização de rodas. Rodas que giram, giram e pouco mudam os modos de trabalhar. Questionar os modos instituídos de trabalhar implica não apenas acessar os processos de trabalho reunidos em dado coletivo, mas realizar ofertas, inspiradas em diretrizes éticoclínicas no campo da saúde coletiva para alterá-los. Implica acionar redes, fomentar grupalidades, provocar multidões em nós...

Essa forma de atuação do apoiador deveria, no limite, vir sempre acompanhada da interrogação: de que intervenção se trata? É apoio? Há coletivo apoiado? Há movimento de mudança operando em alguma direção? Pois a mudança no trabalho é imperiosa e um efeito esperado da função apoio.

\section{Colaboradores}

Os autores trabalharam juntos em todas as etapas de produção do manuscrito.

\section{Referências}

1. Campos GWS. Um método para análise e co-gestão de coletivos - a construção do sujeito, a produção de valor de uso e a democracia em instituições: o Método da Roda. São Paulo: Hucitec; 2000.

2. Ministério da Saúde. Secretaria de Atenção à Saúde. Política Nacional de Humanização. Cadernos HumanizaSUS. Formação e Intervenção [Internet]. Brasília: Ministério da Saúde; 2010 [acesso 2013 Jul 20]. Disponível em: http:// bvsms.saude.gov.br/bvs/publicacoes/cadernos_humanizaSUS.pdf

3. Campos GWS. Memórias de um médico sanitarista que virou professor enquanto escrevia sobre ... São Paulo: Aderaldo \& Rothschild; 2007.

4. Fleury S. Reforma sanitária brasileira: dilemas entre o instituinte e o instituído. Cienc Saude Colet [Internet]. 2009 [acesso 2013 Jul 03]; 14(3):743-52. Disponível em: http://www.scielo.br/scielo.php?script=sci_arttext\&pid=S1413-81232009000300010 \&lng=en. http://dx.doi.org/10.1590/S1413-81232009000300010

5. Campos GWS. O anti-Taylor: sobre a invenção de um método para co-governar instituições de saúde produzindo liberdade e compromisso. Cad Saude Publica [Internet]. 1998 [citado 2014 Jan 12];14(4):863-70. Disponível em: http:// www.scielo.br/scielo.php?script=sci_arttext\&pid=S0102-311X1998000400029 $\& \operatorname{lng}=$ en. http://dx.doi.org/10.1590/S0102-311X1998000400029

6. Campos GWS. Saúde Paideia. São Paulo: Hucitec; 2000. 
FUNÇÃO APOIO: DA MUDANÇA INSTITUCIONAL ...

7. Ministério da Saúde. Secretaria-Executiva. Caderno de referência para o processo de formação de profissionais do Apoio Institucional Integrado do Ministério da Saúde: QUALISUS-REDE. Brasília: MS; 2011. (Série F, Comunicação e Educação em Saúde)

8. Passos E, Benevides R. A cartografia como método de pesquisa-intervenção In: Passos E, Kastrup V, Escóssia L, organizadores. Pistas do método da cartografia: pesquisa-intervenção e produção de subjetividade. Porto Alegre: Sulina; 2009. p. 17-31.

9. Pasche DF, Passos E. Inclusão como método de apoio para a produção de mudanças na saúde - aposta da Política de Humanização da Saúde. Saude Debate. 2010; 34(86):423-32.

Paulon SM, Pasche DF, Righi LB. Función apoyo: desde el cambio institucional a la institucionalización del cambio. Interface (Botucatu). 2014; 18 Supl 1:809-20.

El artículo discute la tensión constitutiva de la función apoyo en su tarea instituyente de proponer acciones junto a colectivos de trabajo en salud que se encuentran limitados en las posibilidades de producir salud para sí mismo y para los demás. Las elaboraciones iniciales del concepto y algunos dilemas encontrados en el curso de experimentaciones de apoyo san debatidos de modo a elucidar cuestiones planteadas en su ejercicio actual, como: ¿Qué puede ser anunciado como apoyo desde su entrada en el SUS como tecnología de cambio sostenida en la expansión de la democracia institucional? ¿Cuáles son los límites actuales para realización de esta función? Estas reflexiones apuntan el cuestionamiento do que los (des)caminos tomados en esta década de experimentaciones afirmam de lo que fue, ha sido y del porvenir del apoyo.

Palabras clave: Políticas públicas de salud. Salud Pública. Sistema Brasileño de Salud. Análisis institucional. Apoyo institucional.

Recebido em 16/07/13. Aprovado em 07/01/14 